\title{
HUBUNGAN POLA MAKAN DAN KEBIASAAN OLAHRAGA YANG BAIK DENGAN KADAR GULA DARAH PENDERITA DIABETES MELLITUS TIPE II DI RSI JEMURSARI
}

\author{
Marlia Alief Rachmawati, Handayani, Adyan Donastin \\ Fakultas Kedokteran, Universitas Nahdlatul Ulama Surabaya \\ e-mail: marlialief@gmail.com
}

\begin{abstract}
Abstrak: Diabetes Mellitus tipe II adalah penyakit kronis mengalami resistansi terhadap aksi insulin dan ketidakmampuan pankreas untuk menghasilkan cukup insulin. DM tipe II sendiri menduduki peringkat ke-2 di dunia dengan penderita terbanyak Pola makan yang buruk dan kurangnya olahraga dapat memengaruhi terjadinya DM tipe II. Perkembangan pola makan yang salah arah saat ini mempercepat peningkatan jumlah penderita DM di Indonesia. Pada saat tubuh melakukan gerakan, maka sejumlah gula akan dibakar untuk dijadikan tenaga gerak. Sehingga sejumlah gula dalam tubuh akan berkurang dan kebutuhan akan hormon insulin juga akan berkurang. Penelitian ini bertujuan adalah untuk mengetahui hubungan pola makan dan kebiasaan olahraga dengan kadar gula penderita Diabetes Mellitus II pada penderita Diabetes Mellitus II di RSI Jemursari Penelitian ini dilakukan dengan metode survey atau observasional dengan pendekatan cross sectional. Sampel yang diambil sebanyak 24 pasien. Populasi dalam penelitian ini adalah semua pasien Diabetes Mellitus Tipe 2 yang menjalani rawat jalan pada poli penyakit dalam, namun dibatasi dengan kriteria inklusi dan eksklusi yang penulis buat. Dari 24 pasien, pada hubungan pola makan dengan kadar gula darah sebanyak 13 pasien $(54,2 \%)$ mempunyai kadar gula tidak tinggi. 11 pasien $(45,8 \%)$ mempunyai kadar gula tinggi. Dengan hasil uji statistik didapatkan nilai $\mathrm{p}=1,000(\mathrm{p}>0,05)$. Maka dapat disimpulkan bahwa terdapat hubungan yang tidak signifikan antara pola makan dan kadar gula. Serta hubungan olahraga dengan kadar gula darah sebanyak 13 pasien $(54,2 \%)$ mempunyai kadar gula tidak tinggi. 11 pasien $(45,8 \%)$ mempunyai kadar gula tinggi. Dengan hasil uji statistik didapatkan nilai $\mathrm{p}=0,432(\mathrm{p}>0,05)$. Maka dapat disimpulkan bahwa terdapat hubungan yang tidak signifikan antara olahraga dan kadar gula.
\end{abstract}

Kata Kunci: pola makan, olahraga,kadar gula darah, diabetes mellitus

\section{PENDAHULUAN}

Diabetes mellitus adalah gangguan metabolisme yang secara genetis dan klinis termasuk heterogen dengan manifestasi berupa hilangnya toleransi karbohidrat. Apabila sudah berkembang penuh secara klinis, maka diabetes mellitus ditandai oleh hiperglikemia, arterosklerotik, mikroangiopati, dan neuropati. ${ }^{1}$

Prevalensi DM di Indonesia mencapai jumlah 8.426 juta pada Tahun 2000 yang diperkirakan akan meningkat pada Tahun 2030 sebesar 21.257 juta, hal ini berarti terjadi kenaikan tiga kali lipat dalam waktu 30 Tahun. Oleh karena itu, menurut laporan World Health Organization (WHO) bahwa pada Tahun 2000 terdapat 1,0 juta penduduk mengalami kematian akibat diabetes dengan prevalensi sekitar 2,0\% dan pada Tahun 2012 dilaporkan bahwa terdapat 1,5 juta penduduk mengalami kematian akibat diabetes dengan prevalensi sekitar 2,7\%. Dari seluruh kematian akibat DM di dunia,70\% kematian terjadi di negara-negara berkembang termasuk Indonesia. ${ }^{2}$

Dengan demikian, penelitian bertujuan untuk mengetahui hubungan pola makan dan 
kebiasaan olahraga dengan kadar gula penderita diabetes mellitus II pada penderita diabetes mellitus II di RSI Jemursari.

Diharapkan penelitian ini dapat memberikan manfaat berupa memberikan informasi pola makan dan olahraga yang baik untuk penderita Diabetes Mellitus II di RSI Jemursari dan untuk mengetahui hubungan pola makan dan olahraga yang baik dengan kadar gula darah penderita diabetes mellitus II di RSI Jemursari serta untuk mengetahui perbandingan hubungan pola makan dengan olahraga terhadap kadar gula darah.

\section{METODE PENELITIAN}

Pada penelitian ini menggunakan metode observasional bersifat deskriptif dengan desain penelitian cross-sectional menggunakan data primer berupa quesioner yang diambil pada bulan September-Oktober 2017.

Pada penelitian ini didapatkan beberapa kriteria inklusi dan kriteria eksklusi. Kriteria inklusi berupa pasien yang datang ke RSI Jemursari melalui IRJ (Poli Umum dan Poli Penyakit Dalam) pada bulan September-Oktober 2017 dan menderita diabetes mellitus, pasien dispeps dengan rentang usia 30-64 tahun, pasien diabetes mellitus yang berjenis kelamin baik laki-laki maupun perempuan, pasien bersedia menjadi responden. Kriteria eksklusi berupa penderita tidak ada komplikasi berat penyakit lain dan tidak minum obat secara rutin.

Penelitian ini menggunakan teknik pengambilan sampel dengan cress sectional mulai September-November 2017. Data yang dijadikan sebagai sampel diambil dari quesioner yang dibagikan kepada pasien yang berada di Rumah Sakit Islam Jemursari Surabaya. Data-data yang telah diperoleh akan diolah menggunakan aplikasi Microsoft Office Excel 2007.

\section{HASIL DAN PEMBAHASAN}

\section{Hasil Penelitian}

Berdasarkan kadar gula, menunjukkan frekuensi kadar gula darah pasien diabetes mellitus II di RSI jemursari adalah sebagian besar adalah rendah dengan frekuensi sebanyak 13 orang $(54,2 \%)$ selanjutnya pada pasien kadar gula tinggi sebanyak 11 orang $(45,8 \%)$.

Berdasarkan pola makan, pola makan responden setengah dari responden melakukan pola makan yang baik sebanyak 12 orang (50\%) sedangkan yang mempunyai pola makan buruk sebanyak 12 orang $(50 \%)$.

Berdasarkan olahraga, responden pasien URJ jemursari sebanyak 9 orang jarang melakukan olahraga dengan persentase $37,5 \%$ dan sebanyak 15 orang $(62,5 \%)$ selalu melakukan olahraga.

Jadi hasil penelitian secara deskriptif semakin tinggi kadar gula makan responden selalu rajin olahraga. Hasil penelitian secara statistik menyatakan terdapat ada hubungan tidak signifikan.

Jadi hasil penelitian secara deskriptif semakin tinggi kadar gulanya makan pola makan seseorang menjadi tidak baik. Sedangkan secara statistik menyatakan terdapat hubungan yang tidak signifikan antara faktor pola makan dengan kadar gula.

Pola makan yang baik dengan kadar gula darah yang tinggi dan tidak tinggi. Pada gula darah yang tinggi didapatkan pasien sebanyak 5 orang dengan persentase $41,7 \%$ sedangkan yang tidak tinggi didapatkan pasien sebanyak 7 orang dengan persentase $58,3 \%$.

Pola makan yang tidak baik dengan kadar gula darah yang tinggi dan tidak tinggi. Pada gula darah yang tinggi didapatkan pasien sebanyak 6 orang dengan persentase $50.0 \%$ sedangkan yang tidak tinggi didapatkan pasien sebanyak 6 orang dengan persentase $50.0 \%$. 
Marlia Alief Rachmawati, Handayani, Adyan Donastin, Hubungan Pola Makan dan Kebiasaan Olahraga yang Baik dengan Kadar Gula Darah Penderita Diabetes Mellitus Tipe II di RSI Jemursari

Olahraga yang rutin dengan kadar gula darah yang tinggi dan tidak tinggi. Pada gula darah yang tinggi didapatkan pasien sebanyak 8 orang dengan persentase $53,3 \%$ sedangkan yang tidak tinggi didapatkan pasien sebanyak 7 orang dengan persentase $46,7 \%$.

Olahraga yang jarang dengan kadar gula darah yang tinggi dan tidak tinggi. Pada gula darah yang tinggi didapatkan pasien sebanyak 3 orang dengan persentase $33.3 \%$ sedangkan yang tidak tinggi didapatkan pasien sebanyak 6 dengan persentase $66.7 \%$.

Pola makan dan olahraga dengan baik mempunyai kadar gula tidak tinggi 55\% dan adalah yang selalu melakukan pola makan dan olahraga dengan baik mempunyai kadar gula $46 \%$.

Pola makan baik dengan jarang olahraga mempunyai kadar gula tinggi tidak didapatkan. Sedangkan yang mempunyai pola makan dengan jarang olahraga mempunyai kadar gula tidak tinggi $100 \%$.

Pola makan tidak baik dengan sering melakukan olahraga mempunyai kadar gula tinggi dengan persentase $50 \%$ melakukan pola makan tidak baik dengan sering melakukan olahraga mempunyai kadar gula tidak tinggi dengan persentase $50 \%$.

Pola makan dengan tidak baik jarang melakukan olahraga mempunyai kadar gula darah dengan persentase $50 \%$ sedangkan yang pola makan tidak baik dengan jarang melakukan olahraga sebanyak $50 \%$.

\section{Pembahasan}

Pada DM tipe I terdapat kerusakan pada sel beta akibat reaksi autoimun, sedangkan pada DM tipe II kadar glukosa darah meningkat karena adanya resistensi insulin akibat gaya hidup yang salah. Diabetes mellitus merupakan suatu kelompok penyakit metabolik dengan karakteristik hiperglikemia yang terjadi karena kelainan sekresi insulin, kerja insulin atau keduanya. ${ }^{3}$

Jenis makanan menentukan kecepatan naiknya kadar gula darah. Kecepatan suatu makanan dalam menaikkan kadar gula darah disebut juga indeks glikemik. Makanan Indeks glikemik tinggi harusnya dihindari seperti sumber karbohidrat sederhana, gula, madu, sirup, roti, mie dan lainlain. Makanan yang berindeks glikemik lebih rendah adalah makanan yang harus dikonsumsi dan kaya dengan serat, contohnya sayuran dan buah-buahan. ${ }^{4}$

Konsumsi makanan yang berlebihan terutama mengandung karbohidrat dan lemak menyebabkan jumlah energi yang masuk ke dalam tubuh tidak seimbang dengan kebutuhan energi. Kelebihan energi ini di dalam tubuh akan disimpan dalam bentuk jaringan lemak yang lamakelamaan akan mengakibatkan obesitas. Asupan serat yang cukup dapat mencegah kejadian obesitas. Serat mengabsorbsi air, memperluas penyerapan di usus, dan memperlambat pergerakan makanan pada saluran pencernaan sehingga menimbulkan rasa kenyang lebih lama. Berdasarkan hasil food recall 24 jam dan food record yang diolah menggunakan nutrisurvey menunjukkan bahwa seluruh subjek belum dapat memenuhi anjuran asupan serat perhari. ${ }^{5}$

Olahraga yang dimaksud dalam penelitian ini adalah olahraga yang dilakukan selama 3 kali dalam seminggu selama 30 menit secara rutin. Olah raga yang kurang menyebabkan makanan yang masuk ke tubuh tidak dibakar melainkan ditimbun sebagai lemak dalam tubuh. Penimbunan lemak tubuh dalam waktu yang lama akan mengakibatkan obesitas. Orang dewasa dengan obesitas akan mempunyai risiko diabetes 24 kali lebih besar. ${ }^{6}$ 
DM II menunjukkan transmisi vertikal sampai 3 generasi. Sedangkan DM I hanya 6\%. Jika salah satu orang tuanya mengalami DM, makan probabilitas anaknya yang terkena $25 \%$ sedangkan kedua orangtuanya yang terkena DM maka 50\% anaknya terkena DM. Apabila pada DM I, orang tuanya terkena DM maka anaknya mempunyai risiko $5-10 \%$ saja. $^{7}$

\section{KESIMPULAN DAN SARAN}

\section{Simpulan}

Berdasarkan hasil penelitian ini dapat disimpulkan hasil yang menunjukkan bahwa terdapat hubungan yang tidak signifikan antara pola makan dengan kadar gula darah pada penderita diabetes mellitus tipe II sedangkan terdapat hubungan yang tidak signifikan antara olahraga dengan kadar gula darah pada penderita diabetes mellitus II. Pengobatan akan dapat berjalan dengan baik jika diberikan bersama dengan pengaturan makan dan latihan jasmani (gaya hidup sehat).

\section{Saran}

Saran penulis, perlu adanya penelitian menggunakan sampel dengan jumlah lebih banyak didapatkan dengan sampel minimal pasien agar memudahkan hubungan antara pola makan dan kebiasaan olahraga dengan kadar gula pasien.

\section{DAFTAR RUJUKAN}

Fatimah R.N. 2015. Diabetes Mellitus Tipe 2. Journal Majority.

Price, S.A. dan Wilson, L.M. 2006. Patofisiologi: Konsep Klinis Proses-. Proses Penyakit, Edisi 6, Volume 1. Jakarta: EGC

Pyke, D.A., and P.G. Nelson. 1976. "Diabetes Mellitus in Identical Twins." Pp. 194-202 in The Genetics of Diabetes Mellitus, edited by W. Creutzfeldt, J. Kobberling, and J.F. Neel. New York.

Rafanani, B. 2013. Buku Pintar Pola Makan Sehat dan Cerdas bagi Penderita Diabetes. Yogyakarta: Penerbit Araska.

Sukardji, K. 2009. Penatalaksanaan Gizi pada Diabetes Mellitus. Dalam: Penatalaksanaan Diabetes Mellitus Terpadu. Jakarta: Pusat Diabetes dan Lipid RSUPN dr. Cipto Mangunkusumo, FKUI.

Suyono, S. 2006. Kecenderungan Peningkatan Jumlah Penyandang Diabetes, dalam Penatalaksanaan Diabetes Mellitus Terpadu. Jakarta: Balai Penerbit FK UI.

WHO. 2014. Diabetes Melitus. Diakses pada 21 Januari 2018. 